\section{Brain Performance Evaluation of Patients Survivors after a Cardiorespiratory Arrest}

Daiana Terra Nacer ${ }^{1}$, Marisa Dias Rolan Loureiro', Anna Letícia Miranda², Isabelle Campos de Azevedo ${ }^{3}$, Marcos Antonio Ferreira Júnior ${ }^{3}$

\title{
Abstract
}

Introduction: Cardiopulmonary arrest (CPA) is the absence of cardiac mechanical activity, confirmed by the absence of detectable pulse, lack of responsiveness and apnea or gasping, and panting.

Objective: To evaluate the brain performance of the adult patients surviving the CPA before it, at discharge and after six months, and to describe the survival of patients six months after hospital discharge.

Methods: This is a descriptive, analytical, prospective study with a quantitative approach, developed in a general philanthropic hospital in the city of Campo Grande, in Mato Grosso do Sul, Midwestern Brazil, with 78 patients surviving for Cardiopulmonary Arrest (CPA).

Results: Regarding CPA, there were $56.4 \%(n=44)$ of cases occurring in the intra-hospital and 30 patients had their hospital discharge. Among the previous diseases, there was hypertension highlighted with $44.9 \%(n=35)$. However, there was no statistically significant difference between the previous average of Cerebral Performance Category (CPC) and CPA and at discharge. Of the 30 patients who had hospital discharge, 21 were followed up after discharge, 14 had CPC 1 at discharge, and 15 had the same index six months later. The average CPC at discharge was 1.47 and six months after, it was 1.42 .

Conclusion: These results enable to understand the gaps in the knowledge of the topic. It is suggested to carry out further research monitoring such patients and recognize the results to facilitate comparisons and contributions to the quality of care in health and decisionmaking.

1 Department of Nursing, Biological Science and Health Center, Federal University of Mato Grosso do Sul, Campo Grande/MS, Brazil.

2 Clinical Hospital of Minas Gerais, Federal University of Minas Gerais, Belo Horizonte/MG, Brazil.

3 Department of Nursing, Health Science Center, Federal University of Rio Grande do Norte, Natal/RN, Brazil.

\section{Contact information:}

\section{Marcos Antonio Ferreira Júnior}

Address: Avenida Salgado Filho, S/N, Lagoa Nova, Natal, RN, Brazil. Zip Code: 59078970.

झ marcos_nurse@hotmail.com

\section{Keywords}

Heart Arrest; Cardiopulmonary Resuscitation; Neurological Rehabilitation. 


\section{Introduction}

Cardiac arrest or cardiopulmonary arrest (CPA) is the absence of cardiac mechanical activity, confirmed by the absence of detectable pulse, lack of responsiveness and apnea or gasping, and panting. The term "cardiac arrest" is more commonly used than "cardiopulmonary arrest" when referring to a patient who is not breathing with no palpable pulse [1].

Despite the advances in recent years related to the prevention and treatment of CPA, there are many lives lost annually in these events. Therefore, it remains a worldwide public health problem. Although there is no exact idea of this problem by the lack of better statistical data, it is estimated at 200,000 CPA events per year in Brazil $[2,3]$.

An accurate evaluation of the patient prognosis after CPA is needed to identify those who benefit from intensive care to prevent unnecessary treatments in those who have no reasonable chance of recovery. The prognosis is considered too dark, not only because of anoxic-ischemic neurological damage, but also the "Post Cardiac Arrest Syndrome" which includes all clinical and biological manifestations related to the phenomenon of ischemia-reperfusion triggered by CPA and the return of spontaneous circulation [4].

The Brazilian Society of Cardiology recommends using brain function scoring system called Cerebral Performance Category (CPC), with a score of one to five, in which one is the best performance and five is the brain death (Table 1) to evaluate the functional pre-event capacity, based on interviews with the family and information recorded at the time of admission, the date of discharge, after six months and one year. For patients who die in the hospital, recording the best CPC achieved is recommended [5].

Nursing professionals play a key role in the management and effective monitoring of hospital cardiac arrest, and they are often the first professionals to be requested at the time of an emergency to start
Table 1. Scores of the Cerebral Performance Category.

\begin{tabular}{|c|c|}
\hline Escore & CPC: Cerebral Performance Category \\
\hline 0 & Hospital Death. \\
\hline 1 & $\begin{array}{l}\text { Good cerebral performance, conscious, alert, } \\
\text { able to work and lead a normal life. May have } \\
\text { minor psychological or neurological deficits } \\
\text { (mild dysphagia, hemiparesis or lower CNS } \\
\text { abnormalities). }\end{array}$ \\
\hline 2 & $\begin{array}{l}\text { Moderate brain impairment: conscious, enough } \\
\text { brain function to work part-time in a protected } \\
\text { environment or independent activities of daily } \\
\text { living (for example, dressing, traveling by public } \\
\text { transportation, food preparation). May have } \\
\text { hemiplegia, seizures, ataxia, dysarthria, dysphagia } \\
\text { or mental or permanent memory changes. }\end{array}$ \\
\hline
\end{tabular}

Severe cerebral disability: conscious, dependent on others for the daily life due to the disability of brain function (for example, living in an institution

3 or at home with exceptional family effort). Having at least limited cognition; including a wide variety of brain abnormalities from paralysis to inability to communicate.

Comatose, vegetative state: not conscious;

4 unaware of their environment without cognitive, verbal or sociability interaction.

5 Brain death/organ donation candidate.

Source: Brazilian Society of Cardiology (2013, p.143).

resuscitation, even before the arrival of the medical team [6].

Due to the importance of this topic, of the need for continuous updating and the existence of few current studies published by the nursing staff, it is recommended the development of investigations that contribute to the qualification of knowledge and the improvement of nursing interventions in the urgent and emergency area [7].

The prediction of an accurate neurological prognosis for comatose patients after CPA is essential to guide the actions at all levels of care and decisions about the end of life. Thus, a study evaluating the neurological condition of patients after CPA can contribute to the development of prognostic strategies for these patients and consequently reduce patient treatment costs [8]. 
Given the above and considering the relevance of the topic presented, this study aimed to evaluate the brain performance of adult patients surviving a CPA before it, at discharge and after six months, and to describe the survival of patients six months after the hospital discharge.

\section{Method}

This is a descriptive, analytical, prospective study with a quantitative approach, developed in a general philanthropic hospital in the city of Campo Grande, in Mato Grosso do Sul (MS), Midwestern Brazil. The first phase of data collection took place between November 2014 to May 2015 in the general and cardiology Adult Intensive Care Unit, with 78 survivors of CPA. The second stage took place six months after hospital discharge of these patients.

At first, the data were collected in electronic medical records and patients were identified through daily visits to the sectors mentioned before. In the second time, the patients were evaluated through home visits or telephone contact, when the visit was not possible.

Patients younger than eighteen, indigenous, maroons, pregnant women and people deprived of freedom were excluded from the sample. Also, those cases where it was not possible to collect data for lack of information, are reduced or insufficient in medical records were excluded.

After collection, the data were stored in spreadsheets Microsoft Office Excel $®$ program. Statistical analysis was performed using SPSS, version 22.0, considering a 5\% significance level. Regarding the variables, age, gender, previous diseases and average hospitalization time, the results are presented as mean (average standard error) or relative frequency (absolute frequency). A comparison of the pre- and post-CPA in relation to CPC was performed using the Wilcoxon test. The other results are presented in the form of descriptive statistics or in the form of tables and graphs.
This research followed the recommendations of Resolution No 466 of 12 December 2012, of the National Health Council [8], and authorized by the Ethics Committee in Research of the Federal University of Mato Grosso do Sul, adopted on November 2, 2014, under opinion $N^{\circ} 856,096$.

\section{Results}

There were 78 patients surviving a CPA evaluated in this study, while in 44 of them (56.4\%), the first event occurred in the intra-hospital environment. Regarding their evolution, 30 patients (38.5\%) survived to hospital discharge. Among them, when analyzing the site of the first CPA, $44.1 \%$ occurred in patients outside the hospital environment and $34.1 \%$ in the intra-hospital environment.

The age of the patients ranged from 18 to 100 years old, and the average was 62.09 (2.05) years old. Most of them were men, 44 patients (56.4\%). Among the previous diseases, hypertension was highlighted in 35 patients (44.9\%), and the average length of stay was 28.45 (3.35) days.

Vasoactive drug was required in $79.5 \%$ of patients, 37.2\% had sepsis and $34.6 \%$ renal failure. The main causes of hospitalization were infection and heart disease, $17.9 \%$ each, followed by trauma, acute myocardial infarction, among others. Most of the study participants had two CPA events, 44.9\%, with an average of $1.91 \pm 0.12$ events/patient.

Table 2 shows the results of the evaluation of the CPC of patients before CPA and at discharge, but also the best value indicators reached in the case of patients that died.

It was noted that of the 30 patients had hospital discharge, 96.7\% had CPC 1 before the CPA, and $72.7 \%$ had the same CPC at discharge, while the 48 patients that died, $87.4 \%$ had CPC 1 before the CPA and $81.2 \%$ had CPC 4 as the best score achieved during hospitalization.

The CPC at hospital discharge for patients who survived or the best score achieved during hospitali- 
Table 2. Comparison of the Index Cerebral Performance Category of patients who had hospital discharge and death during this research, Campo Grande/MS, 2015 ( $n=78)$.

\begin{tabular}{|c|c|c|c|c|c|c|}
\hline \multirow[b]{2}{*}{ CPC } & \multicolumn{2}{|c|}{ Discharge } & \multicolumn{2}{|c|}{ Death } & \multicolumn{2}{|c|}{ Total } \\
\hline & $\begin{array}{c}\text { Pre } \\
\text { arrest } \\
(n=30) \\
n \%\end{array}$ & $\begin{array}{c}\text { At } \\
\text { discharge } \\
(n=30) n \\
\%\end{array}$ & $\begin{array}{c}\text { Pre } \\
\text { arrest } \\
(n=48) \\
n \%\end{array}$ & $\begin{array}{c}\text { Better } \\
\text { score } \\
(n=48) \\
n \%\end{array}$ & $\begin{array}{c}\text { Pre } \\
\text { arrest } \\
(n=78) \\
n \%\end{array}$ & $\begin{array}{c}\text { Discharge } \\
\text { or better } \\
\text { score } \\
(n=78) n \\
\%\end{array}$ \\
\hline 1 & $\begin{array}{c}29 \\
(96.7)\end{array}$ & $\begin{array}{c}22 \\
(72.7)\end{array}$ & $\begin{array}{c}42 \\
(87.4)\end{array}$ & $\begin{array}{c}01 \\
(2.1)\end{array}$ & $\begin{array}{c}71 \\
(91.0)\end{array}$ & $\begin{array}{c}23 \\
(29.5)\end{array}$ \\
\hline 2 & $\begin{array}{c}00 \\
(0.0)\end{array}$ & $\begin{array}{c}04 \\
(13.2)\end{array}$ & $\begin{array}{c}01 \\
(2.1)\end{array}$ & $\begin{array}{c}02 \\
(4.2)\end{array}$ & $\begin{array}{c}01 \\
(1.3)\end{array}$ & $\begin{array}{c}06 \\
(7.7)\end{array}$ \\
\hline 3 & $\begin{array}{c}1.0 \\
(3.3)\end{array}$ & $\begin{array}{c}04 \\
(13.2)\end{array}$ & $\begin{array}{c}5 \\
(10.5)\end{array}$ & $\begin{array}{c}04 \\
(8.3)\end{array}$ & $06(7.7)$ & $\begin{array}{c}08 \\
(10.2)\end{array}$ \\
\hline 4 & $\begin{array}{c}00 \\
(0.0)\end{array}$ & $\begin{array}{c}00 \\
(0.0)\end{array}$ & $\begin{array}{c}00 \\
(0.0)\end{array}$ & $\begin{array}{c}39 \\
(81.2)\end{array}$ & $\begin{array}{c}00 \\
(0.0)\end{array}$ & $\begin{array}{c}39 \\
(50.0)\end{array}$ \\
\hline 5 & $\begin{array}{c}00 \\
(0.0)\end{array}$ & $\begin{array}{c}00 \\
(0.0)\end{array}$ & $\begin{array}{c}00 \\
(0.0)\end{array}$ & $\begin{array}{c}02 \\
(4.2)\end{array}$ & $\begin{array}{c}00 \\
(0.0)\end{array}$ & $\begin{array}{c}02 \\
(2.6)\end{array}$ \\
\hline
\end{tabular}

zation for patients that died was significantly higher when compared to the previous evaluation to CPA as shown in Figure 1.

Figure 1: Brain Performance before the CPA and at discharge or higher value at death among patients treated in intra-hospital and extra-hospital environments.

\section{Cerebral Performance Category (1 to 5 points)}

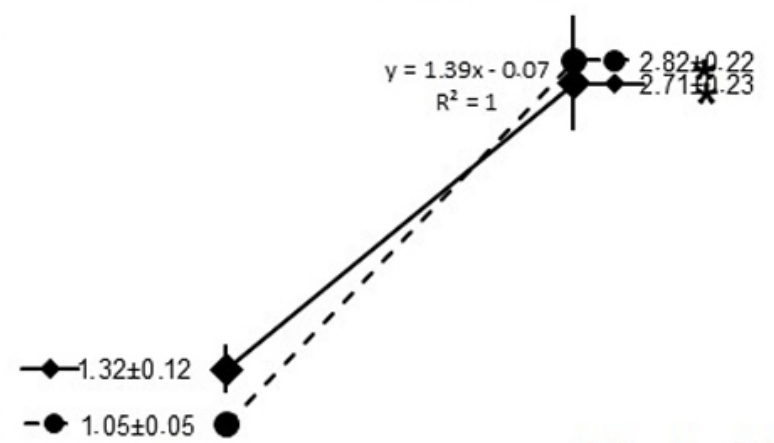

$\multimap$ Extra-hospital

Moment related to the Cardiopulmonary arrest (CPA)

Each symbol represents the average, and the bar is the standard error of the average. *: Significant difference pre-CPA (Wilcoxon test, $p<0.001)$.
However, when discharged patients were evaluated there was no significant difference compared to the previous CPC to CPA and at discharge, according to data in Table 3.

Table 3. Comparison of Cerebral Performance Category Index among patients who had discharge and death in extra-hospital environments, Campo Grande/MS, 2015 ( $n=78$ ).

\begin{tabular}{|c|c|c|}
\hline \multirow[b]{2}{*}{ Factors } & \multicolumn{2}{|c|}{ Place of Cardiopulmonary Arrest } \\
\hline & $\begin{array}{l}\text { Extra-hospital } \\
\qquad(n=34)\end{array}$ & $\begin{array}{l}\text { Intra-hospital } \\
\qquad(n=44)\end{array}$ \\
\hline \multicolumn{3}{|l|}{ Discharge } \\
\hline Previous CPC & $1.00(0.00)$ & $1.13(0.52)$ \\
\hline Discharge CPC & $1.40(0.74)$ & $1.40(0.74)$ \\
\hline$p$ & 0.125 & 0.250 \\
\hline \multicolumn{3}{|l|}{ Death } \\
\hline Previous CPC & $1.58(0.90)$ & $1.00(0.00)$ \\
\hline Higher score CPC & $3.74(0.56)$ & $3.55(1.15)$ \\
\hline$p$ & $<0.001$ & $<0.001$ \\
\hline
\end{tabular}

The results are presented as an average(standard error of the average). The $p$-value in the Wilcoxon test

Regarding the follow-up after discharge of the 30 patients, there were 21 alive after six months, and two had new hospitalization and death from infection in the following six months. The outcome of the 30 patients is shown in Table 4.

Regarding the analysis of the CPC, the 30 patients who developed high, 14 patients had high and CPC 115 the same index six months. The average CPC

Table 4. Outcome of patients who have suffered cardiac arrest after six months of hospital discharge, Campo Grande/MS, 2015 $(n=30)$.

\begin{tabular}{|c|c|}
\hline Evolution & n (\%) \\
\hline Alive & $21(70)$ \\
\hline Death & $02(07)$ \\
\hline Not founded & 07 (23) \\
\hline Total & 30 (100) \\
\hline
\end{tabular}


on high was 1.47 and six months was 1.42 , data are shown in Table 4. (Table 5)

Table 5. Cerebral Performance Category Index (CPC) at hospital discharge and six months after, Campo Grande/MS, 2015. ( $\mathrm{N}=21)$.

\begin{tabular}{|c|c|c|}
\hline CPC score & At hospital discharge & $\mathbf{6}$ months after \\
\hline 1 & 14 & 15 \\
\hline 2 & 4 & 3 \\
\hline 3 & 3 & 3 \\
4 & 0 & 0 \\
5 & 0 & 0 \\
\hline
\end{tabular}

\section{Discussion}

The successful of the CPA is determined by the individual neurological outcome of each patient. Predicting neurological outcome has enormous ethical and socio-economic implications. Isolating factors that may be related to mortality and irreversible brain injury is relevant for allowing more accurate identification of patients likely to benefit from resuscitation and post-resuscitation intensive care [10].

Among the study participants before to CPA, there were 91\% having CPC 1 with a good cerebral performance, and $29.5 \%$ of them have kept this value as the best score achieved during hospitalization. However, $50 \%$ of patients had CPC 4 (comatose state) after (PA.

The National Registry of Cardiopulmonary Resuscitation of the United States of America (USA) with 14,720 adult patients showed all patients were evaluated for brain performance, and $48.5 \%$ had CPC 1 before the CPA, and $36.7 \%$ maintained this score as the best value. However, when analyzing only patients with hospital discharge, $68 \%$ had CPC 1 before CPA, and $58.7 \%$ left the hospital with the same brain performance, without new neurological damage [11]. Meanwhile, the results of this research show that $96.7 \%$ had CPC 1 and $72.7 \%$ had the same score at discharge.
By analyzing the whole group, there was a statistically significant difference between the previous CPC to CPA and at discharge or best score achieved. However, when only the patients who survived to hospital discharge were evaluated, there was no significant difference between the previous brain performance and discharge (extra-hospital CPA: $p=0.125$; intra-hospital CPA: $p=0.250$ ), which indicates that patients left the hospital without worsening of their brain function.

The data allowed stating that there is a good quality of cardiopulmonary resuscitation with favorable neurological outcomes for patients with discharge. However, further research should be conducted to demonstrate which factors determine these outcomes and how they can identify the patients who would benefit from resuscitation with the good neurological outcome and which patients inevitably will evolve to death inside the hospital, despite repeated resuscitation.

Researchers analyzed the data during 10 years from a large national record of US in-hospital resuscitation. While survival rates in hospital discharge increased, significant neurological disability (CPC score higher than 1) among the survivors decreased over time in the overall cohort, from 32.9\% in the first year of the research to $28.1 \%$ in the last year [12].

Survival after CPA has improved significantly over the last decade in hospitals participating in the North American records. This improvement was mainly attributed to improved survival during acute resuscitation and accompanied by a simultaneous reduction of neurological disability rate over time. Identifying the factors responsible for these improvements in trends and expanding these processes to other installations is justifiable and necessary [12].

Regarding the follow-up after discharge, 70\% of patients in this study were alive in the first six months, 7\% were dead, and 23\% were not found. In a similar study with 49 patients monitored survi- 
ving CPA the sixth-month mortality was $2 \%$. However, $22 \%$ of the participants could not be reached. Also, the neurological status of patients was evaluated using various measures and analyzes revealed that the scores have improved over time [14].

While the average CPC at discharge among the subjects of this study was 1.47 and six months after discharge was 1.42, a study conducted in the US showed the average CPC of the patients of 1.97 at discharge, and 1.76 after six months [12]. The study results confirm and indicate that neurological recovery despite slow continues for months after hospital discharge.

In a study with 98 patients who remained comatose after resuscitation from cardiac arrest, 45 patients survived to 1 month. Improvements in functional status occur over the first 6 months after the event. There was no significant change in outcome between postarrest months 6 and 12 [14].

In a study in Sweden with survivors of CPA, it was found that those with CPC 3 after one year showed significant neurological improvement since they were reclassified with CPC 1 and 2 [15].

Despite discrepancies between studies on neurological recovery in various periods of time, all demosntram good results after hospital discharge.

In a study that followed 285 patients treated with CPA, $56.3 \%$ survived to discharge and showed improvement or maintained previous CPC to the event. After six months of follow-up, $53.8 \%$ of patients remained with the same CPC and $46.2 \%$ improved the CPC about their score at discharge. After a year of follow-up, all patients remained with the same CPC in the previous six months [8].

\section{Conclusion}

The CPA remains as an event that leads to survival and outcome variables. Despite the limitations of this study, as non-standardized records and the difficulty for comparisons due to different methodologies on existing works, the results showed good neurological recovery for patients who had hospital discharge.

Data from individuals monitored after discharge showed that the recovery process is slow and at the same time necessary, given the importance of these patients receive follow-up to ensure better recovery and disposal of specialized rehabilitation services. But the studies also differ on the period in which the recovery of these patients continues. Several factors need to be better explained by encouraging more research in the area.

The process of resuscitation and post-cardiac arrest care are most often initiated and carried out by the nursing staff. Scientific research on the subject impact and strengthen the care provided to these patients and demonstrate the relevance of nursing as a producer of scientific knowledge.

There are few current studies involving survivors to CPA. The documentation of these results is important and essential, so gaps are understood on the subject. It is suggested that research conducts monitoring of such patients and recognize the results to facilitate comparisons and contributions to the quality of care in health and decision-making.

\section{References}

1. Aehlert B. ACLS, suporte avançado de vida em cardiologia: emergências em cardiologia. 4. Ed. Rio de Janeiro: Elsevier; 2013. 424p.

2. Sociedade Brasileira de Cardiologia. I Diretriz de Ressuscitação Cardiopulmonar e Cuidados Cardiovasculares de Emergência da Sociedade Brasileira de Cardiologia. Arq Bras Cardiol. 2013; 101(supp. 3): 1-221. Available from: http://publicacoes.cardiol. br/consenso/2013/Diretriz Emergencia.pdf

3. Nacer DT, Loureiro MDR, Miranda AN, Azevedo IC, Ferreira Júnior MA. Cardiopulmonary arrest survival related to hospital discharge in adults. International Archives of Medicine. 2016; 9(177): 1-8. Available from: http://imed.pub/ojs/index.php/iam/ article/view/1736

4. Mongardon N, Dumas F, Ricome S, Grimaldi D, Hissem T, Pène F, Cariou A. Postcardiac arrest syndrome: from immediate resuscitation to long-term outcome. Ann Intensive Care. 2011; 1(1): 45. Available from: http://www.ncbi.nlm.nih.gov/pmc/ articles/PMC3223497/ 
5. Sociedade Brasileira de Cardiologia. Diretriz de apoio ao suporte avançado de vida em cardiologia - Código Azul - Registro de Ressuscitação Normatização do Carro de Emergência. Arq Bras Cardiol. 2003; 8(supl. 4): 1-14. Available from: http://www. scielo.br/pdf/abc/v81s4/20229.pdf

6. Pothitakis C, Ekmektzoglou KA, Piagkou M, Karatzas T, Xanthos T. Nursing role in monitoring during cardiopulmonary resuscitation and in the peri-arrest period: a review. Heart Lung. 2011; 40(6): 530-44. Available from: http://www.heartandlung. org/article/S0147-9563(10)00466-8/fulltext

7. Luzia MF, Lucena AF. Parada cardiorrespiratória do paciente adulto no âmbito intra-hospitalar: subsídios para a enfermagem. Rev Gaúcha Enferm. 2009; 30(2): 328-37. Available from: http://seer.ufrgs.br/index.php/RevistaGauchadeEnfermagem/ article/view/5638/6692

8. Vancini-Campanharo $C R$, Vancini $R L$, Lira $C A B$, Lopes MCBT, Okuno MFP, Batista REA, et al. One-year follow-up of neurological status of patients after cardiac arrest seen at the emergency room of a teaching hospital. Einstein. 2015; 13(2): 183-8. Available from: http://www.scielo.br/pdf/eins/ v13n2/1679-4508-eins-13-2-0183.pdf

9. Brasil. Resolução n. 466, de 12 de dezembro de 2012. Dispõe sobre diretrizes e normas regulamentadoras de pesquisas envolvendo seres humanos. Diário Oficial da República Federativa do Brasil; 2012. Seção 1. p. 59-62.

10. Rech TH, Vieira SRR, Brauner JS. Serum Neuron-Specific Enolase as a Prognostic Marker after a Cardiac Arrest. Rev. bras. ter. intensiva.. 2006; 18(4): 396-401. Available from: http://www. scielo.br/pdf/rbti/v18n4/13.pdf

11. Peberdy MA, Kaye W, Ornato JP, Larkin GL, Nadkarni V, Mancini $\mathrm{ME}$, et al. Cardiopulmonary resuscitation of adults in the hospital: A report of 14720 cardiac arrests from the National Registry of Cardiopulmonary Resuscitation. Resuscitation. 2003; 58(3): 297-308. Available from: http://www.resuscitationjournal.com/ article/S0300-9572(03)00215-6/fulltext

12. Girotra S, Nallamothu BK, Spertus JA, Li Y, Krumholz HM, Chan PS. Trends in Survival After In-Hospital Cardiac Arrest. N Engl J Med. 2012; 367(20): 1912-20. Available from: http://www.nejm. org/doi/full/10.1056/NEJMoa1109148\#t=article
13. Raina KD, Rittenberger JC, Holm MB, Callaway CW. Functional Outcomes: One Year after a Cardiac Arrest. BioMed Research International. 2015; 2015: 1-8. Available from: http://www. hindawi.com/journals/bmri/2015/283608/

14. Tong JT, Eyngorn I, Mlynash $M$, Albers GW, Hirsch KG. Functional Neurologic Outcomes Change Over the First 6 Months After Cardiac Arrest. Crit Care Med. 2016 Aug 5. Avaliable from: http://www.ncbi.n/m.nih.gov/pubmed/27495816

15. Martinell L, Larsson $M$, Bang A, Karlsson T, Lindqvist J, Thorén $A B$, Herlitz J. Survival in out-of-hospital cardiac arrest before and after use of advanced postresuscitation care: a survey focusing on incidence, patient characteristics, survival, and estimated cerebral function after postresuscitation care. Am J Emerg Med. 2010; 28(5): 543-51. Available from: http://www.ajemjournal. com/article/S0735-6757(09)00067-9/fulltext
Publish in International Archives of Medicine

International Archives of Medicine is an open access journal publishing articles encompassing all aspects of medical science and clinical practice. IAM is considered a megajournal with independent sections on all areas of medicine. IAM is a really international journal with authors and board members from all around the world. The journal is widely indexed and classified Q2 in category Medicine. 